\section{THE GAUR Bos GAURUS SMITH, 1827 IN KAWAL WILDLIFE SANCTUARY, ANDHRA PRADESH}

\section{Srinivasulu}

Research Associate (Wildlife), Wildlife Biology Section, Department of Zoology, University College of Science (A), Osmania University, Hyderabad, Andhra Pradesh 500007, India.

Email:masawa@hd2.dot.net.in

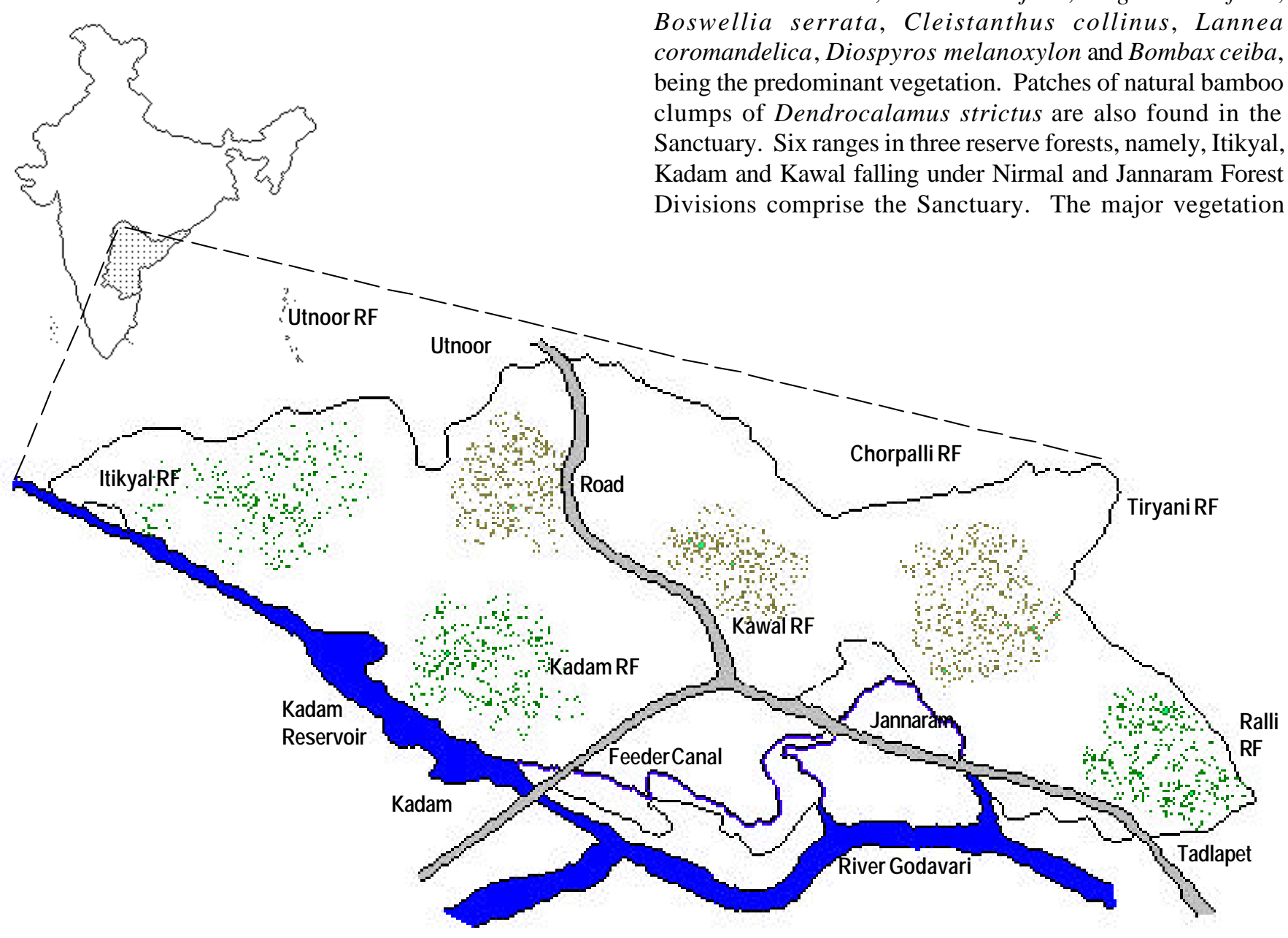

Arsikota RF
Between 1997 and 1999 surveys were carried out in different areas of the Kawal Wildlife Sanctuary to determine the habitat preferences of cervids and other ungulates. During these surveys details of indirect evidence of Gaur (Bos gaurus Smith, 1827) presence were noted to determine their distribution within the Sanctuary. All cattle herders who frequented the interior areas of the Sanctuary and the local trackers appointed for tracking tiger movements were the main source for approximation of number of individuals that roamed in particular areas of the Sanctuary.

Kawal Wildlife Sanctuary $\left(19^{\circ} 05^{\prime}-19^{\circ} 20^{\prime} \mathrm{N}\right.$ and $\left.78^{\mathrm{O}} 32^{\prime}-79^{\circ} 12^{\prime} \mathrm{E}\right)$ covering an area of $893 \mathrm{~km}^{2}$, is located in Adilabad District of Andhra Pradesh. It has undulating topography, with hills on the northern boundary and a gentle slope towards Godavari River flowing $6-12 \mathrm{~km}$ from the southern boundary of the Sanctuary (Fig. 1). The forest is of southern tropical dry deciduous type (Champion \& Seth, 1968) with Tectona grandis, Terminalia tomentosa, Terminalia arjuna, Anogeissus latifolia, Boswellia serrata, Cleistanthus collinus, Lannea coromandelica, Diospyros melanoxylon and Bombax ceiba, being the predominant vegetation. Patches of natural bamboo clumps of Dendrocalamus strictus are also found in the Sanctuary. Six ranges in three reserve forests, namely, Itikyal, Kadam and Kawal falling under Nirmal and Jannaram Forest Divisions comprise the Sanctuary. The major vegetation

Figure 1. Map of Kawal Wildlife Sanctuary depicting areas of Gaur Bos gaurus strongholds 
composition found in these reserve forests are teak mixed miscellaneous forest and teak mixed bamboo forest. Teak mixed bamboo forest is more dominant (55\%) than the teak mixed miscellaneous forest $(40 \%)$, while the remaining areas are either teak plantations, scrub areas or village enclosures (Srinivasulu, in press).

Of the six ranges (namely - Birsaipet, Jannaram, Indhanpally, Tadlapet, Kadam and Pembi) that comprise the Sanctuary, evidence of presence of Gaur was recorded from five (Table 1). In the past, Gaurs have been reported in good numbers from Kadam Range, but during the study period they were not observed there. Strongholds of population were recorded from the Birsaipet and Indhanpally Ranges. A population of about 30 to 35 individuals lives in the contiguous areas of Rampur and Dosthunagar beats. Once we missed sighting a strong herd of 27 individuals ( 7 males, 13 females, and 7 sub adults and calves, as detailed later by a cattle herder who saw the herd) crossing Panchanadula Stream moving towards the Panchanodula Valley in Rampur Beat.

My tracker informed me about a herd of 18-26 individuals frequenting Nalakonda Shivar area of the Dosthunagar Beat. In this area, my colleagues and I had to take to heels for safety when we approached too close to a lone male! In the bid to escape we missed a chance to sight this elusive yet magnificent creature. A herd of 10-12 animals were reported from Udumpur area. This area along with Rampur and Dosthunagar form a large tract of Gaur and Tiger potential habitat of the Sanctuary that also has a respectful population of other wild fauna. Along the Pedda Vagu Stream in the Kalleda Beat a herd of 8-12 individuals was reported. It is here where herbivores, like the Nilgai Boselaphus tragocamelus and the ChitalAxis axis, are found in abundance.

In Tadlapet Range, about 8-20 individuals and 10-28 individuals were reported from Malyal and Gopparloddi areas, respectively. Another strong population was reported to occur in Pembi Range. Here, local herders saw good number of this species from Donga Chelma (c' 18-26 individuals) and Domadhari (c' 1220) areas.

Kawal Wildlife Sanctuary is one among the few areas in the Godavari River basin that still is a home to Gaur. In this tract Gaur numbers have depleted over the years mainly due to manifestations of rinderpest and foot-and-mouth disease. Gaurs are also reported from other protected areas like Eturnagaram; Pakhal and Kinnerasani wildlife sanctuaries, and also in the reserve forests interspersing these protected areas in the districts of Adilabad, Karimnagar, Warangal, Khammam and West Godavari. Our studies in Karimnagar District indicate that Gaur populations in reserve forest areas are under great threat due to livestock grazing pressure and diseases. Cattle herders have reported frequent deaths of Gaur in these tracts due to FMD; and they believe that it is the Gaur that causes loss to their cattle by infecting them. In Kawal Wildlife Sanctuary, the primary threat to Gaur is the livestock grazing pressure and exposure to disease carriers as both the livestock and Gaur use the same grazing grounds. Besides this, another important factor is the deaths caused due to drowning in the feeder canals from the Kadam Reservoir that meanders through the Sanctuary. Many individuals in their bid to cross the barrier drown in the feeder canals, as they are not able to climb the sloping concrete banks. During the summer months, when the water is scarce, other animals get attracted to these canals as they have small pools of water and meet the same fate, albeit not by drowning but by exhausting themselves attempting in vain to climb the banks. Mysterious deaths have been also reported during summer months when these animals drink from drying water holes holding very little water that concentrates to form broth of salts laced with bacteria. Animals dying due to this cause do not exhibit any external manifestation of injuries or bleeding.

\section{Acknowledgement}

I thank Dr. V. Nagulu for his encouragement, Mr. G. Ravinder, Forest Range Officer (Wildlife) and Linganna, animal tracker of Kawal Wildlife Sanctuary for their help; and acknowledge the fellowship grant from CSIR, New Delhi.

\section{References}

Champion, H.G. and S.K. Seth (1968). A Revised Survey of Forest Types of India. Govt. of India, New Delhi.

Srinivasulu, C. (in press). Birds of Kawal Wildlife Sanctuary, Andhra Pradesh, India. Journal of the Bombay Natural History Society 